\title{
ANÁLISE DA DISTRIBUIÇÃO ESPACIAL DOS EMPREGOS NO MUNICÍPIO DE PALMAS-TO
}

\author{
William Brasil Rodrigues Sobrinho ${ }^{1}$ \\ Rodolfo Alves da Luz \\ Nilton Marques de Oliveira ${ }^{3}$
}

Resumo: O trabalho buscou mensurar e analisar a distribuição espacial do emprego no município de Palmas-TO. Foi utilizada a base de dados da FIETO (Federação das Indústrias do Estado do Tocantins), relativos a 477 das 738 empresas localizadas no município de Palmas-TO. O presente trabalho se diferencia dos demais em razão do nível da abordagem utilizada quando da análise da distribuição espacial do emprego em escala municipal. O Quociente Locacional (QL) foi a métrica utilizada para indicar a concentração relativa de uma determinada atividade econômica no município de Palmas-TO. Os resultados indicam que $42,3 \%$ dos empregos estão preenchidos nas indústrias de transformação enquanto. Algumas atividades econômicas resultaram em quocientes locacionais bem elevados (QL > 7), a exemplo da eletricidade e gás $(Q L=7,32)$ na região noroeste; alojamento e alimentação (QL = 10,90); água, esgoto, atividade de gestão de resíduos e descontaminação obtiveram $(\mathrm{QL}=8,18)$ e indústrias extrativas $(\mathrm{QL}=8,06)$, ambas na região sul.

Palavras-chave: Emprego. Análise Regional. Economia Regional. Quociente Locacional. Atividade Econômica.

\section{ANALYSIS OF THE SPACE DISTRIBUTION OF EMPLOYMENT IN THE MUNICIPALITY OF PALMAS-TO}

\begin{abstract}
This paper measures and analyses the spatial distribution of employment in the municipality of Palmas-TO. Database from the FIETO (Industry Federation of the State of Tocantins), was used, considering 477 out of a total of 738 companies located in the municipality of Palmas-TO. This work differs from the others due to the level of the approach used, which analyzes the spatial distribution of employment at the municipal scale. The Locational Quotient (LQ) was the metric used to indicate the relative concentration of the economic activity in the city. The results indicate that $42.3 \%$ of the jobs are filled in the manufacturing industries while some economic activities resulted in very high locational quotients $(L Q>7)$, such as electricity and gas $(L Q=7.32)$ in the northwest region; accommodation and food $(L Q=10.90)$; water, sewage, waste management and decontamination activities $(L Q=8.18)$ and extractive industries $(\mathrm{LQ}=8.06)$, both in the southern region.
\end{abstract}

Keywords: Employment. Regional Analysis. Regional Economics. Locational Quotient. Economic Activity.

\footnotetext{
1 Instituto Federal do Tocantins (IFTO), Programa de Pós-Graduação em Desenvolvimento Regional PPGDR, Palmas, Brasil, william.rodrigues@mail.uft.edu.br, https://orcid.org/0000-0002-7993-8266

2 Universidade Federal do Tocantins (UFT), Programa de Pós-Graduação em Desenvolvimento Regional - PPGDR, Palmas, Brasil, rodolfodaluz@mail.uft.edu.br, https://orcid.org/0000-0002-66084898

3 Universidade Federal do Tocantins (UFT), Programa de Pós-Graduação em Desenvolvimento Regional - PPGDR, Palmas, Brasil, niltonmarques@mail.uft.edu.br, https://orcid.org/0000-0001-6485$314 X$
} 


\section{ANÁLISIS DE LA DISTRIBUCIÓN ESPACIAL DE LOS EMPLEOS EN EL CIUDAD DE PALMAS-TO}

Resumen: El trabajo buscó medir y analizar la distribución espacial del empleo en el ciudad de Palmas-TO. Se utilizaron la base de datos de la FIETO (Federación de las Industrias del Estado de Tocantins) relativos a 477 de 738 empresas ubicadas en el ciudad de Palmas-TO. El presente trabajo se diferencia de los demás en razón del nivel de abordaje utilizado en el análisis de la distribución espacial del empleo a escala municipal. El Cociente Locacional (QL) fue la métrica utilizada para indicar la concentración relativa de una determinada actividad económica en Palmas-TO. Los resultados indican que el $42,3 \%$ de los empleos están llenos en las industrias de transformación mientras que algunas actividades económicas resultaron en cocientes locacionales muy elevados ( $Q L>7$ ), a ejemplo de la electricidad y el gas $(\mathrm{QL}=7,32)$ en la región noroeste; alojamiento y alimentación $(\mathrm{QL}=10,90)$; el agua, alcantarillado, actividad de gestión de residuos y descontaminación $(Q L=8,18)$ y las industrias extractivas $(\mathrm{QL}=8,06)$, ambas en la región sur.

Palabras clave: Empleo. Análisis Regional. Economía Regional. Cociente Locacional. Actividad Económica.

\section{Introdução}

Trabalhos que analisam o desempenho do emprego nos setores da economia são correntes na literatura especializada. É comum a utilização de modelos de indicadores para compreender ou melhor visualizar a mudança da distribuição dos postos de empregos ou padrões locacionais em uma determinada região, seja ela a nível nacional, regional, estadual ou microrregiões a exemplo os trabalhos de Lodder (1974), Staduto et al. (2008), Ramos (2007), Piacenti, Alves e Lima (2008), Paiva (2006) e Domingues (2005).

Contudo as estatísticas disponíveis em nível regional ou estadual não garantem uma segura compreensão dos deslocamentos industriais, enquanto isso em nível municipal a averiguação de distribuição do produto industrial é crítica, em função carência e qualidade das estatísticas existentes (ANDRADE; SERRA, 2000). Diante disso o presente trabalho busca mensurar e analisar a distribuição espacial do emprego no município de Palmas-TO. Para isso foram levantados os dados relativos a localização das empresas, bem como o quantitativo de empregos gerados por empresa. Adicionalmente foram apresentados dados relacionados aos aspectos relacionados a participação no mercado exterior por meio do levantamento das empresas exportadoras, bem como das empresas envolvidas em projetos de inovação. 
Embora grande parte dos trabalhos que analisam a distribuição espacial dos empregos formais tenham como premissa de análise a variação dos empregos ao longo do tempo (PIACENTI; ALVES; LIMA, 2008; STADUTO et al., 2008). Alguns trabalhos anteriores realizados a nível do estado do Tocantins contemplam como análise as antigas microrregiões do estado vide Barbosa et al., (2019), Carvalho et al., (2018) e Oliveira et al., (2018). O presente trabalho parte da premissa de apresentar a situação da distribuição espacial do emprego em escala municipal.

Conforme dados do IBGE relativos ao ano de 2016, Palmas-TO capital do estado do Tocantins, contempla um território de $2.218,942 \mathrm{~km}^{2}$, uma população estimada de 286.687 habitantes, PIB per capta de $R \$ 28.974$, sendo que o pessoal ocupado totalizava 136.013 e o salário médio dos trabalhadores era de 3,8 salários mínimos (considere $\mathrm{R} \$ 880$ o valor do salário-mínimo).

O trabalho possui além desta introdução outras quatro seções. A seção seguinte aborda uma breve revisão da literatura, seguida da apresentação da metodologia enquanto isso na quarta seção são apresentados os dados bem como realizada a análise dos resultados. Na última seção são realizadas as últimas considerações deste trabalho.

\section{Distribuição espacial do Emprego nos Setores Econômicos}

Nas regiões Norte e Nordeste, considerando o período de 1985-2000, houve uma ampliação da produção de bens manufaturados. Conforme Piacenti, Alves e Lima (2008) houve uma tendência de crescimento do emprego ao final do século $\mathrm{XX}$, embora tais regiões tenham dificuldades em termos de investimentos e melhoria na qualidade de vida. Em termos mais específicos o setor primário ganhou mais postos de trabalhos na região de expansão da fronteira agrícola. Há de se ressaltar que em razão dessa expansão, os estados do Tocantins, Mato Grosso e Goiás, bem como alguns estados da região Nordeste, a exemplo da Bahia e Ceará, considerando o período de 1995-2000, registraram crescimentos de empregos formais acima da média nacional (RAMOS, 2007).

Embora o estudo de Lobo e Matos (2010), tenha enfatizado a região de São Paulo, devido a diversos fatores, tais como a relevância da influência do estado em grande parte do território nacional, torna-se importante a discussão da espacialização do emprego em escalas menores (por exemplo, em nível municipal), devido a produção de resultados mais específicos. 
O papel da especialização (relevância de determinadas atividades em detrimento das demais) para 0 processo de desenvolvimento permanece sem consenso na literatura econômica. O trabalho de Breitbach (2005) demonstra que regiões diversificadas são capazes de contribuir para o desenvolvimento local, por meio de uma "revalorização de suas características endógenas". Enquanto isso Paiva (2006) argumenta que a especialização é condição necessária para o desenvolvimento de uma determinada região.

A utilização de indicadores auxilia no entendimento e na identificação de disparidades regionais, mostrando as regiões que merecem maior atenção. As medidas de localização demonstram quais são as regiões ou setores mais especializados. Com o auxílio das medidas de especialização é possível verificar as modificações ocorridas em uma determinada região no decorrer do tempo (ALVES, 2012).

É comum também a utilização de indicadores de localização e especialização para análises relativas ao uso de terras, proporcionando um quadro de análise do uso das terras nos estados em relação a uma determinada região específica (LIMA et al., 2006).

Um dos indicadores considerado o mais utilizado pelos pesquisadores diz respeito ao Quociente Locacional (QL), basicamente O QL informa o quanto determinado setor é mais (ou menos) relevante (ou especializado) para a região analisada. "Além disso, essas medidas, ao utilizarem o peso relativo do número de empregados, anulam as perturbações introduzidas pelas disparidades de dimensões das regiões" (PIACENTI; ALVES; LIMA, 2008, p. 484).

A utilização do Quociente Locacional (QL) para determinar se um município em particular possui especialização em uma atividade específica é largamente utilizado nos trabalhos acadêmicos. Tradicionalmente na literatura voltada para a economia regional, o QL compara duas estruturas setoriais-espaciais. Ele é a razão entre duas estruturas econômicas: no numerador tem-se a "economia" em estudo e no denominador uma "economia de referência" (CROCCO et al., 2006).

\section{Metodologia}

Dados da Pesquisa

Os dados relacionados aos estabelecimentos comerciais do município de Palmas-TO, foram obtidos por meio do Guia Industrial do Tocantins. O respectivo 
guia é elaborado pela FIETO - Federação das Indústrias do Estado do Tocantins, referentes ao ano de 2017 e disponibilizado no seguinte endereço eletrônico http://guiaindustrial.fieto.com.br. Os acessos para a extração dos dados foram realizados entre os dias 21 e 26 de janeiro de 2019. Prioritariamente os dados se referem a estabelecimentos industriais situados em Palmas-TO e contemplam informações relacionadas a endereço, número de empregados, CNAE, porte da empresa, exportadora e se produz inovação.

Foram coletados os dados de 617 empresas registradas no município de Palmas-TO. Após obtenção dos dados houve a exclusão das empresas específicas da Construção de Edifícios (Código CNAE, Divisão 41), tal exclusão se justifica em razão da impossibilidade de identificar a localização das obras, tendo em vista que os empregos estão alocados apenas no endereço da sede, o que resultaria em imprecisão da localização dos empregos.

Adicionalmente foram excluídas as empresas de serviços públicos, tais como a companhia de Distribuição de Energia, Água e Correios do Tocantins, com base nos mesmos critérios explanados anteriormente. A manutenção destas empresas ocasionaria imprecisão no tratamento e apresentação dos dados. Por fim, foram excluídas as empresas que apresentaram inconsistência nos dados de endereço (localização), ou seja, nestes casos não foi possível identificar a quadra na qual está situada a empresa, devido possivelmente a erro de cadastro no sistema. A amostra final do estudo contempla os dados de 477 empresas situadas no plano diretor do munícipio de Palmas-TO.

Os arquivos vetoriais foram processados no software QGIS Desktop versão 3.4.5-Madeira (LTS). Os dados vetoriais do município de Palmas-TO, foram obtidos por meio do Sistema de Informações Geográficas de Palmas, disponibilizado no seguinte endereço eletrônico http://geo.palmas.to.gov.br/, acessado no mês de janeiro de 2019. Os demais arquivos vetoriais foram obtidos no Portal de Mapas do IBGE-Instituto Brasileiro de Geografia e Estatística, disponibilizado no seguinte endereço eletrônico https://portaldemapas.ibge.gov.br, acessado no mês de janeiro de 2019.

Quociente Locacional (QL)

Seguindo trabalhos anteriores Staduto et al., (2008), foi estimado o Quociente Locacional (QL) para indicar a concentração relativa de uma determinada 
atividade econômica numa região, comparativamente à participação dessa mesma atividade econômica no Município, no caso deste trabalho. Neste aspecto, quanto maior o QL, maior é a especialização da região no respectivo ramo de atividade. 0 quociente locacional é expresso pela equação (1).

$$
Q L_{i j}=\frac{E_{i j} / \sum_{j} E_{i j}}{\sum_{i} E_{i j} / \sum_{i} \sum_{j} E_{i j}}
$$

Em que:

$$
\begin{aligned}
& E_{i j}=\text { Número de empregados no ramo de atividade } i \text { da região } j ; \\
& \sum_{j} E_{i j}=\text { Número de empregados no ramo de atividade } i \text { de todas as regiões; } \\
& \sum_{i}^{i} E_{i j}=\text { Número de empregados em todos os ramos de atividade da região } j ; \\
& \sum_{i} \sum_{j} E_{i j}=\text { Número de empregados em todos os ramos de atividade e todas as regiões. } \\
& \text { Neste modelo consideram-se como atividades ou ramos básicos de maior }
\end{aligned}
$$
concentração aqueles para os quais o valor do quociente locacional for superior a 1 , nestes casos essas atividades econômicas teriam uma produção que excederia as necessidades locais, marcando a especialização relativa da região (STADUTO et al., 2008).

A cidade de Palmas-TO, é considerada uma região geográfica intermediária pelo IBGE (2017), localizada na região central do Tocantins. Para fins de melhor visualização e identificação o plano diretor da cidade foi dividido em 5 (cinco) regiões administrativas, conforme demonstrado na figura 1 a seguir. 
Figura 1 - Localização do Município de Palmas-TO e suas Regiões Administrativas
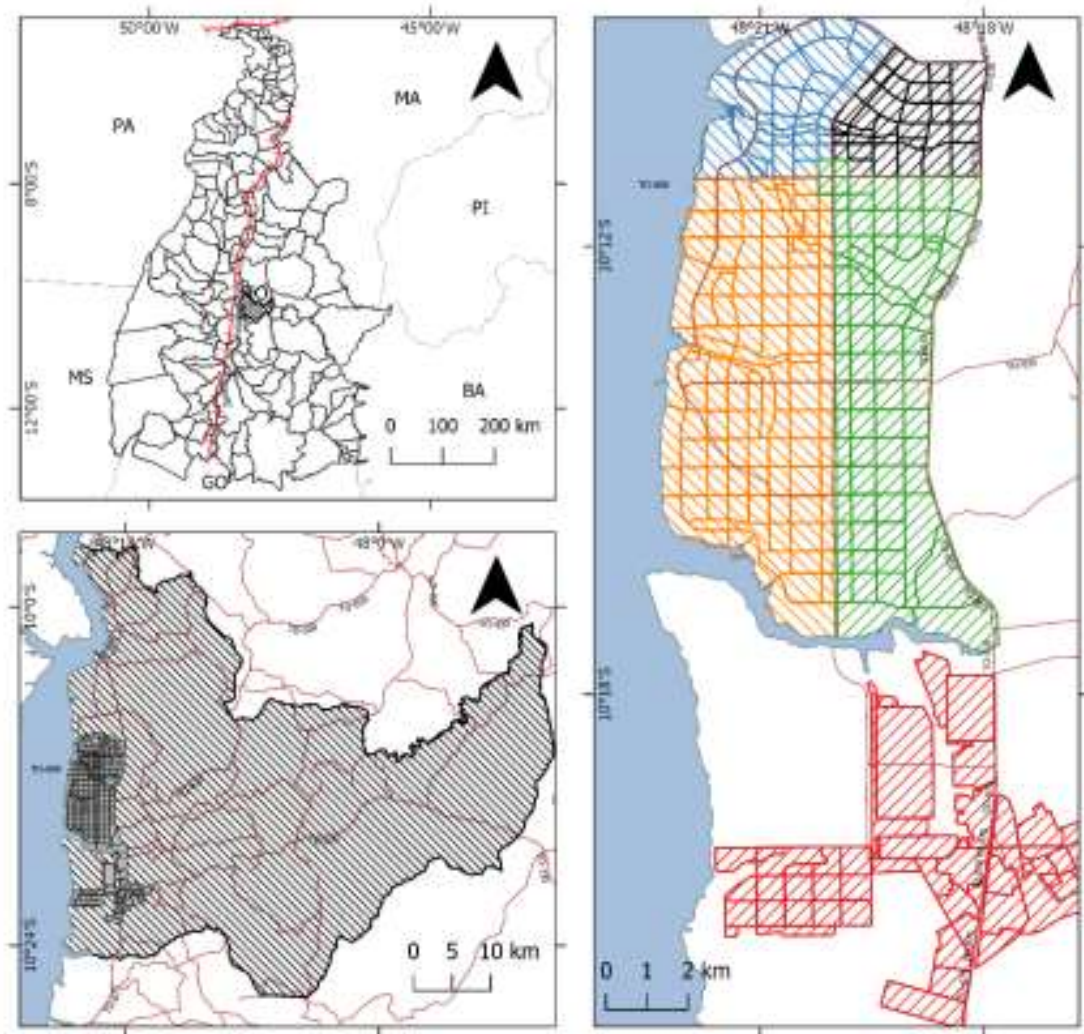

Legenda

Brasil

$\square$ Tocantins

Lago da UHE - Lajeado

+ Ferrovia Norte-Sul

- Rodovias Estaduais

Ex Palmas-TO

$\square$ Plano Diretor de Palmas-TO

एव Regiz̄o Adm. Sul de Paimas

Regiäo Adm. Sudoeste de Paimas

CZ Região Adm. Sudeste de Palmas

$\triangle$ Regiảo Adm. Noroeste de Palmas

एב Regiăo Adm. Nordeste de Paimas

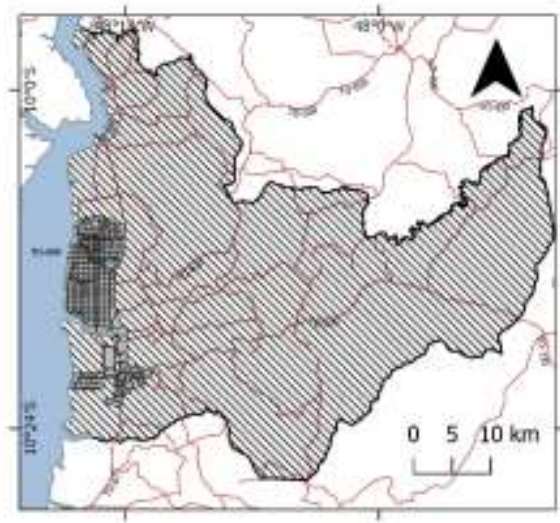

Fonte: Elaborado pelos autores com dados do IBGE - Portal de Mapas e Sistema de Informações Geográficas de Palmas-TO

As regiões se dividem de acordo com sua localização as quais tem como eixos norteadores a Avenida Juscelino Kubitschek (Av. JK) a qual cruza o plano diretor em sentido Leste-Oeste e a Avenida Teotônio Segurado que cruza o plano diretor de Palmas-TO no sentido Norte-Sul. As quadras podem ser localizadas em razão do cruzamento entre essas avenidas. A exceção a esta regra diz respeito a região Sul de Palmas-TO, a qual tem como divisor um braço do Lago da UHELajeado que separa a região Sul, mais conhecida como região dos Aurenys e Taquaralto do restante do plano diretor de Palmas-TO. Fazem ainda parte da cidade de Palmas-TO, dois distritos: Taquaruçu e Buritirana os quais não são tratados neste trabalho.

\section{Apresentação e Análise dos Resultados}

Apresentação dos dados

A tabela 1 a seguir apresenta a composição dos 7.062 empregos na região de Palmas-TO distribuídos nas respectivas atividades econômicas, conforme estrutura da CNAE. 
Tabela 1 - Quantitativos de empregos em Palmas-TO por atividade econômica ano 2017

\begin{tabular}{|c|c|c|}
\hline Atividade Econômica & Empregos & AV\% \\
\hline Indústrias de Transformação & 2.985 & $42,3 \%$ \\
\hline Construção & 1.831 & $25,9 \%$ \\
\hline Comércio; Reparação de Veículos Automotores E Motocicletas & 1.154 & $16,3 \%$ \\
\hline Atividades Profissionais, Científicas e Técnicas & 455 & $6,4 \%$ \\
\hline Informação e Comunicação & 372 & $5,3 \%$ \\
\hline Indústrias Extrativas & 131 & $1,9 \%$ \\
\hline Eletricidade e Gás & 64 & $0,9 \%$ \\
\hline Atividades Imobiliárias & 24 & $0,3 \%$ \\
\hline Atividades Administrativas e Serviços Complementares & 22 & $0,3 \%$ \\
\hline Água, Esgoto, Atividades de Gestão De Resíduos e Descontaminação & 12 & $0,2 \%$ \\
\hline Outras Atividades de Serviços & 10 & $0,1 \%$ \\
\hline Alojamento e Alimentação & 2 & $0,0 \%$ \\
\hline Total & 7.062 & $100 \%$ \\
\hline
\end{tabular}

Obs. As atividades econômicas foram obtidas pelos códigos da estrutura da CNAE, os quais foram omitidos por conveniência.

Fonte: Dados da Pesquisa.

Observa-se que a maior parte dos postos de emprego estão presentes na Indústria de Transformação com 42,3\%, o que representa 2.985 empregos; em sequência o setor de Construção com 25,9\%, o equivalente a 1.831 empregos e o setor de Reparação de Veículos Automotores e Motocicletas com 16,3\%, ou seja, 1.154 postos de trabalho. As atividades econômicas relacionadas as atividades profissionais, cientificas e técnicas representam 6,4\% enquanto a Informação e Comunicação contempla 5,3\% dos postos de trabalho no município. Estas cinco atividades econômicas em conjunto agregam o montante de $96,2 \%$ dos empregos presentes na região de Palmas-TO.

A tabela 2 a seguir apresenta as informações a respeito do quantitativo de empresas por atividade econômica, bem como o quantitativo de empresas que realizam algum tipo de exportação e se estão envolvidas em algum projeto de inovação.

Tabela 2 - Empresas por Atividade Econômica/Exportadoras e Inovadoras

\begin{tabular}{lccc}
\hline \multicolumn{1}{c}{ Atividade Econômica } & Empresas & Exporta & Inovação \\
\hline Indústrias de Transformação & 238 & 25 & 92 \\
Comércio; Reparação de Veículos Automotores e Motocicletas & 131 & 9 & 36 \\
Construção & 53 & 4 & 19 \\
Atividades Profissionais, Científicas e Técnicas & 23 & 2 & 12 \\
Informação e Comunicação & 12 & 1 & 4 \\
Indústrias Extrativas & 10 & 0 & 1
\end{tabular}


Eletricidade e Gás

Água, Esgoto e Gestão de Resíduos e Descontaminação

Atividades Administrativas e Serviços Complementares

Alojamento e Alimentação

Atividades Imobiliárias

Outras Atividades de Serviços

\begin{tabular}{lccc} 
& 1 & 0 & 0 \\
& 1 & 0 & 1 \\
Total & 1 & 0 & 1 \\
\hline
\end{tabular}

Obs. As atividades econômicas foram obtidas pelos códigos da estrutura da CNAE, os quais foram omitidos por conveniência.

Fonte: Dados da Pesquisa.

Das 477 empresas que fazem parte da amostra aproximadamente 50\%, ou seja, 238 empresas são do setor da Indústria de Transformação, enquanto 131 $(27,5 \%)$ são do setor de Comércio; Reparação de Veículos Automotores e Motocicletas; 53 (11,1\%) são do setor de Construção; 23 (4,8\%) são do setor de Atividades Profissionais, Científicas e Técnicas e 12 (2,5\%) são Informação e Comunicação, juntam representam 95,8\% da amostra.

Das empresas presentes na amostra 41 (8,6\%), estão envolvidas em atividades de exportação e estão presentes nos seguintes setores: Indústrias de Transformação (25); Comércio, Reparação de Veículos Automotores e Motocicletas (9); Construção (4); Atividades Profissionais, Científicas e Técnicas (2) e Informação e Comunicação (1). Enquanto isso 167 o que representa 35\% da amostra possuem algum projeto de inovação, a maioria das empresas envolvidas em projetos de inovação são relacionadas a indústria de transformação com um total de 92 empresas.

Em consulta as estatísticas do INPI - Instituto Nacional da Propriedade Industrial, a cidade de Palmas-TO possui um total de 207 marcas registradas e 16 patentes depositadas, destas 11 são de invenção e 5 de modelo de utilidade e ainda possui o registro de 2 programas de computadores. O estado do Tocantins possui 330 marcas registradas e 21 patentes depositadas junto ao INPI.

Adicionalmente foi verificado que das 477 empresas presentes na amostra, 363 são classificadas como Microempresa (ME); 60 - Empresa de Pequeno Porte (EPP), 35 - Microempresário Individual MEI, 15 - Empresário Individual e 4 Empresa de Grande Porte (EGP). 
Análise do Quociente Locacional (QL)

A tabela 3 a seguir apresenta a distribuição dos empregos no município de Palmas dividido por atividade econômica e as regiões administrativas adotadas no trabalho. A maior parte dos postos de trabalhos são alocados na região Sudeste com 3.869 (54,8\%) empregos, seguido da região Nordeste com 1.576 (22,3\%) empregos e região Sul de Palmas, com 648 (9,2\%) dos postos de trabalho.

Devido ao rompimento do planejamento inicial da capital, às vezes pelo próprio governo, ocasionou uma desocupação desordenada, impulsionando as populações mais carentes para áreas mais distantes da região central (SOUSA, 2015). Diante desse modelo de ocupação, tendeu à cidade a formação de vazios urbanos, contribuindo para que os mecanismos de formação de preço e de acesso à terra empurrassem a maioria da população de baixa renda para a região de expansão sul (KRAN; FERREIRA, 2006). É provável que o modelo de distribuição dos empregos na cidade se submeta a esse processo histórico de ocupação desordenada da cidade.

Tabela 3 - Distribuição dos empregos por Região Administrativa e Atividade Econômica

\begin{tabular}{|c|c|c|c|c|c|c|}
\hline \multirow{2}{*}{ Atividades Econômicas } & \multicolumn{5}{|c|}{ Regiões Administrativas } & \multirow{2}{*}{ Total } \\
\hline & Nordeste & Noroeste & Sudeste & Sudoeste & Sul & \\
\hline $\begin{array}{l}\text { Água, Esgoto, Atividades de Gestão } \\
\text { De Resíduos e Descontaminação }\end{array}$ & 3 & & & & 9 & 12 \\
\hline Alojamento e Alimentação & & & & & 2 & 2 \\
\hline $\begin{array}{l}\text { Atividades Administrativas e Serviços } \\
\text { Complementares }\end{array}$ & & & 22 & & & 22 \\
\hline Atividades Imobiliárias & & & 24 & & & 24 \\
\hline $\begin{array}{l}\text { Atividades Profissionais, Científicas e } \\
\text { Técnicas }\end{array}$ & 15 & 129 & 258 & 53 & & 455 \\
\hline $\begin{array}{l}\text { Comércio; Reparação de Veículos } \\
\text { Automotores e Motocicletas }\end{array}$ & 81 & 188 & 639 & 192 & 54 & 1.154 \\
\hline Construção & 414 & 141 & 1.153 & 68 & 55 & 1.831 \\
\hline Eletricidade e Gás & & 39 & & 20 & 5 & 64 \\
\hline Indústrias de Transformação & 787 & 88 & 1.654 & 36 & 420 & 2.985 \\
\hline Indústrias Extrativas & & & 32 & & 99 & 131 \\
\hline Informação e Comunicação & 276 & 3 & 77 & 12 & 4 & 372 \\
\hline Outras Atividades de Serviços & & & 10 & & & 10 \\
\hline Total & 1.576 & 588 & 3.869 & 381 & 648 & 7.062 \\
\hline
\end{tabular}

Obs. As atividades econômicas foram obtidas pelos códigos da estrutura da CNAE, os quais foram omitidos por conveniência.

Fonte: Dados da Pesquisa.

A tabela 4 a seguir apresenta o Quociente Locacional (QL) do município de Palmas dividido por atividade econômica e as 5 regiões administrativas. Dentre as 
atividades que são relevantes em suas respectivas regiões destacam-se na região administrativa Nordeste a atividade de Informação e Comunicação com um QL de 3,33. Na região administrativa Noroeste têm-se o ramo de Eletricidade e Gás $(Q L=$ 7,32). A região administrativa Sudeste apresenta relevância em atividades de cunho administrativo ambas com $\mathrm{QL}=1,82$.

A região administrativa Sudoeste por sua vez, apresenta relevância no ramo de Eletricidade e Gás ( $Q L=5,79)$, bem como na atividade de Comércio; Reparação de Veículos Automotores e Motocicletas $(Q L=3,09)$. Enquanto isso a região Sul possui três atividades mais relevantes, tais como, Alojamento e Alimentação $(\mathrm{QL}=$ 10,90), Água, Esgoto, Atividade de Gestão de Resíduos e Descontaminação (QL = 8,18) e Indústrias Extrativas $(\mathrm{QL}=8,06)$.

Tabela 4 - Quociente Locacional de Palmas-TO por Região Administrativa e Atividade Econômica

\begin{tabular}{|c|c|c|c|c|c|}
\hline \multirow{2}{*}{ Atividades Econômicas } & \multicolumn{5}{|c|}{ Regiões Administrativas } \\
\hline & Nordeste & Noroeste & Sudeste & Sudoeste & Sul \\
\hline $\begin{array}{l}\text { Água, Esgoto, Ativ. de Gestão de } \\
\text { Resíduos e Descontaminação }\end{array}$ & 1,12 & - & - & - & 8,18 \\
\hline Alojamento e Alimentação & - & - & - & - & 10,90 \\
\hline $\begin{array}{l}\text { Atividades Administrativas e Serviços } \\
\text { Complementares }\end{array}$ & - & - & 1,82 & - & - \\
\hline Atividades Imobiliárias & - & - & 1,82 & - & - \\
\hline $\begin{array}{l}\text { Atividades Profissionais, Científicas e } \\
\text { Técnicas }\end{array}$ & 0,15 & 3,41 & 1,03 & 2,16 & - \\
\hline $\begin{array}{l}\text { Comércio; Reparação de Veículos } \\
\text { Automotores e Motocicletas }\end{array}$ & 0,31 & 1,96 & 1,01 & 3,09 & 0,51 \\
\hline Construção & 1,01 & 0,93 & 1,15 & 0,69 & 0,33 \\
\hline Eletricidade e Gás & - & 7,32 & - & 5,79 & 0,85 \\
\hline Indústrias de Transformação & 1,18 & 0,35 & 1,01 & 0,22 & 1,53 \\
\hline Indústrias Extrativas & - & - & 0,48 & - & 8,06 \\
\hline Informação e Comunicação & 3,33 & 0,10 & 0,38 & 0,60 & 0,12 \\
\hline Outras Atividades de Serviços & - & - & 1,82 & - & - \\
\hline
\end{tabular}

Obs. As atividades econômicas foram obtidas pelos códigos da estrutura da CNAE, os quais foram omitidos por conveniência.

Fonte: Dados da Pesquisa.

A figura 2 a seguir apresenta os Quocientes Locacionais (QL) de algumas atividades das regiões no município de Palmas-TO. Foram apresentadas as atividades que possuem uma maior variação dos QL's identificados no município em questão.

As atividades que possuem uma maior variação foram as: Atividades Profissionais, Científicas e Técnicas; Comércio; Reparação de Veículos Automotores 
e Motocicletas, Construção, Eletricidade e Gás, Indústrias de Transformação e Informação e Comunicação.

Figura 2 - Quociente Locacional (QL) do Município de Palmas-TO

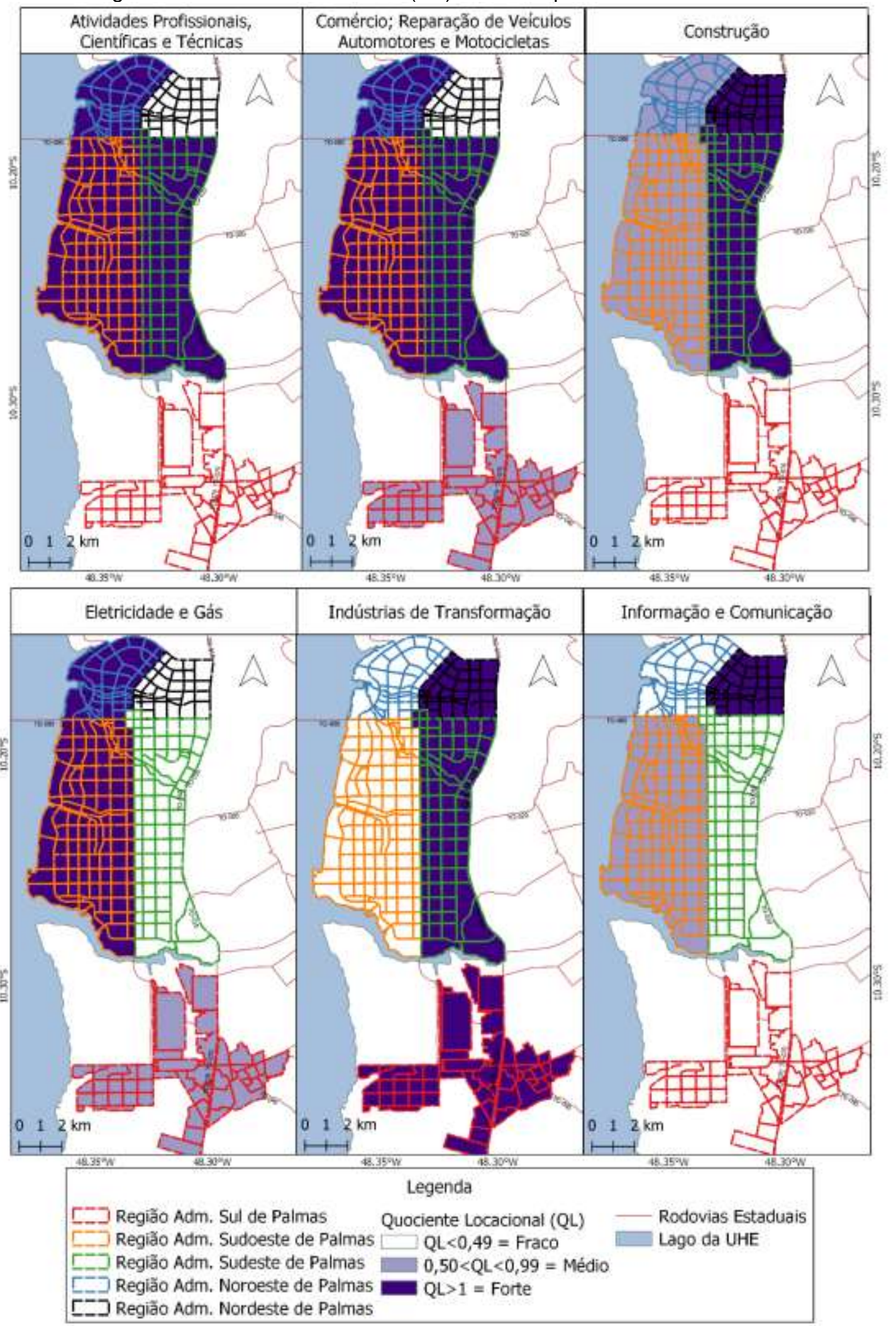

Fonte: Elaborado pelos autores com dados da pesquisa e do IBGE - Portal de Mapas e Sistema de Informações Geográficas de Palmas-TO

Análise da Distribuição Espacial dos Empregos no Município de Palmas-TO 
Por fim, conforme visualização da figura 3, observa-se que a maior parte dos empregos são alocados nas regiões administrativas nordeste, sudeste e sul de Palmas-TO. As regiões administrativas noroeste e sudoeste não possuem uma ocupação considerável por parte das empresas. Pode-se ressaltar que as quadras localizadas nestas regiões são destinadas com uso preferencialmente residencial, ou contemplam os vazios urbanos típicos de Palmas-TO (SILVA, 2010).

Figura 3 - Distribuição Espacial do Emprego em Palmas-TO
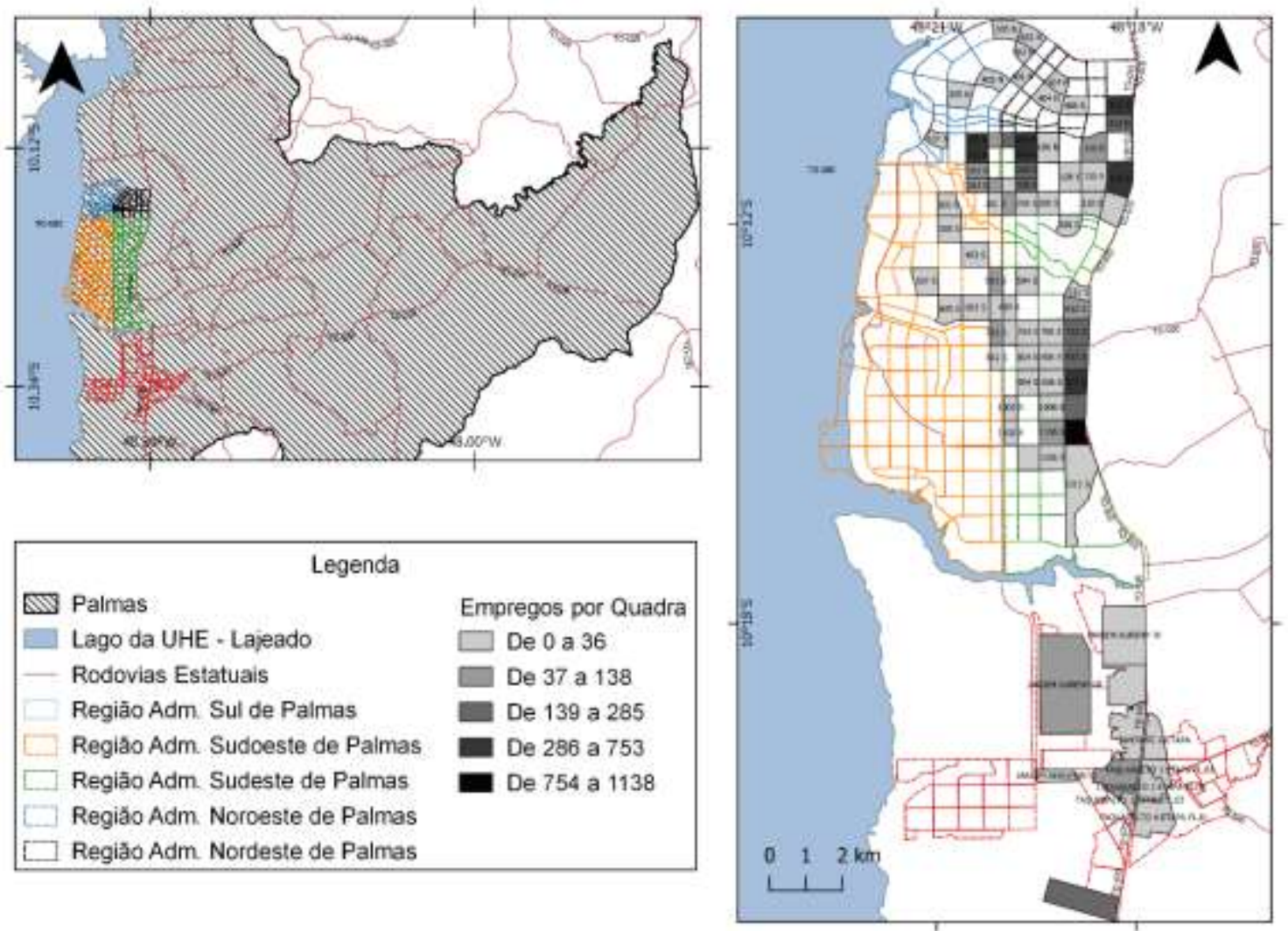

Fonte: Elaborado pelos autores com dados da pesquisa e do IBGE - Portal de Mapas e Sistema de Informações Geográficas de Palmas-TO.

Foi verificada a distribuição dos empregos nas quadras com maiores números de empregos. A quadra 1.112 Sul possui um montante de 1.138 postos de trabalhos, o que representa $16,1 \%$ dos empregos e em sequência a quadra 912 Sul possui 754 postos de emprego localizados, ambas localizadas na região sudeste da capital. 


\section{Considerações Finais}

Este trabalho buscou mensurar e analisar a distribuição espacial do emprego no município de Palmas-TO. Foram apresentados os dados dos empregos por atividade econômica, bem como os quocientes locacionais por regiões administrativas.

Os resultados demonstraram que $42,3 \%$ dos empregos estão preenchidos nas indústrias de transformação. Adicionalmente foi possível verificar que $(54,8 \%)$ dos empregos são localizados na região administrativa sudeste de Palmas-TO, em razão disso há uma maior pulverização dos empregos nas atividades econômicas da região.

Em análise dos quocientes locacionais destacam-se os de Eletricidade e Gás $(\mathrm{QL}=7,32)$ da região administrativa Noroeste e na região administrativa Sul as atividades de Alojamento e Alimentação ( $Q L=10,90)$, Água, Esgoto, Atividade de Gestão de Resíduos e Descontaminação $(\mathrm{QL}=8,18)$ e Indústrias Extrativas $(\mathrm{QL}=$ $8,06)$ apresentaram quocientes locacionais elevados.

Uma das principais limitações do presente trabalho diz respeito a representatividade dos dados coletados. Tendo em vista que os dados obtidos não são relativos a toda a população de empresas localizadas no município de PalmasTO, tais achados devem ser interpretados considerando o tamanho da amostra. Há de se ressaltar ainda que, a maior parte dos empregos do município de Palmas-TO são gerados pela administração pública (OLIVEIRA; PIFFER, 2016).

Novos trabalhos são necessários tendo em vista a limitação da amostra utilizada neste estudo. Nesses próximos estudos podem ser considerados a inclusão ou correção dos dados das empresas que foram excluídas na presente amostra como forma de aumentar a abrangência do estudo. Podem ser considerados ainda, a utilização de outros indicadores locacionais e a utilização de outros modelos estatísticos, a depender do interesse do pesquisador.

\section{REFERÊNCIAS}

ALVES, L. R. Indicadores de localização, especialização e estruturação regional. In: PIACENTI, C. A.; LIMA, J. F. DE (Org.). Análise Regional: metodologias e indicadores. Curitiba, PR: Camões, 2012. p. 33-50.

ANDRADE, T. A.; SERRA, R. V. Distribuição Espacial da Indústria: Possibilidades Atuais para a sua Investigação. Estudos Econômicos (São Paulo), v. 30, n. 2, p. 207-231, 2000. 
BARBOSA, G. F. et al. Polos Econômicos do Tocantins: Uma Proposta de Regionalização Espacial. Revista Brasileira de Gestão e Desenvolvimento Regional, v. 15, n. 2, p. 90-99, 2019.

BREITBACH, Á. C. M. Entre especialização e diversificação industrial: por um desenvolvimento regional durável. Perspectiva Econômica, v. 1, n. 2, p. 1-30, 2005.

CARVALHO, W. Q. et al. Análise locacional das atividades produtivas na microrregião de porto nacional do estado do Tocantins. Economia \& Região, v. 6, n. 1, p. 47-63, 2018.

CROCCO, M. A. et al. Metodologia de identificação de aglomerações produtivas locais. Nova Economia, v. 16, n. 2, p. 211-241, 2006.

DOMINGUES, E. P. Aglomerações e periferias industriais no Brasil e no Nordeste. Revista Econômica do Nordeste, v. 36, n. 4, p. 508-523, 2005.

FIETO. Guia Industrial do Tocantins. Disponível em: <http://guiaindustrial.fieto.com. br>, 2017. Acesso em 21 de janeiro de 2019.

IBGE. Cidades e Estados do Brasil. Instituto Brasileiro de Geografia e Estatística. Disponível em: <https://cidades.ibge.gov.br>, 2018. Acesso em 20 de janeiro de 2019.

IBGE. Portal de Mapas. Disponível em: <https://portaldemapas.ibge.gov.br>. Acesso em 22 de janeiro de 2019.

KRAN, F.; FERREIRA, F. P. M. Qualidade de vida na cidade de Palmas - TO: uma análise através de indicadores habitacionais e ambientais urbanos. Ambiente \& Sociedade, v. 9, n. 2, p. 123-141, 2006.

LIMA, J. F. DE et al. O uso das terras no sul do Brasil: uma análise a partir de indicadores de localização. Revista de Economia e Sociologia Rural, v. 44, n. 4, p. 677-694, 2006.

LOBO, C.; MATOS, R. Dispersão espacial da população e do emprego formal nas regiões de influência do Brasil contemporâneo. Cadernos Metrópole. v. 12, n. 24, p. 309-330, 2010.

LODDER, C. A. Padrões locacionais e desenvolvimento regional. Revista Brasileira de Economia, v. 28, n. 1, p. 3-128, 1974.

OLIVEIRA, N. M. DE; PIFFER, M. Conjuntura do desenvolvimento regional dos municípios do estado do Tocantins. DRd - Desenvolvimento Regional em debate, v. 6, n. 3, p. 32-61, 2016.

OLIVEIRA, N. M. et al. Localização dos Setores Produtivos na Geoeconomia da Microrregião do Rio Formoso, TO. COLÓQUIO, v. 15, n. 2, p. 215-232, 2018.

PAIVA, C. Á. N. Desenvolvimento regional, especialização e suas medidas. Indicadores Econômicos FEE, v. 34, n. 1, p. 89-102, 2006.

PIACENTI, C. A.; ALVES, L. R.; LIMA, J. F. DE. O perfil locacional do emprego setorial no Brasil. Revista Econômica do Nordeste, v. 39, n. 3, p. 482-502, 2008.

RAMOS, L. Evolução e realocação espacial do emprego formal - 1995-2005.

Econômica, v. 9, n. 1, p. 89-112, 2007. 
SILVA, V. C. P. DA. Palmas, a última capital projetada do século XX: uma cidade em busca do tempo: Editora UNESP, 2010.

SOUSA, R. M. DE. A Expansão Urbana do Plano Diretor de Palmas: Uma Análise Jurídica Acerca da Disputa do Espaço Urbano em Palmas/TO. Vertentes do Direito, v. 2, n. 2, p. 40-66, 2015.

STADUTO, J. A. R. et al. Análise locacional das ocupações nas regiões metropolitana e não metropolitana do estado do Paraná. Revista de Economia, v. 34, n. 2, p. 117-139, 2008.

\section{NOTAS DE AUTOR}

\section{CONTRIBUIÇÃO DE AUTORIA}

William Brasil Rodrigues Sobrinho - Concepção. Coleta de dados, Análise de dados e Elaboração do manuscrito.

Rodolfo Alves da Luz - Elaboração do manuscrito. Validação, revisão e aprovação da versão final do trabalho. Nilton Marques Oliveira - Elaboração do manuscrito. Revisão e aprovação da versão final do trabalho.

\section{FINANCIAMENTO}

Não se aplica.

CONSENTIMENTO DE USO DE IMAGEM

Não se aplica.

\section{APROVAÇÃO DE COMITÊ DE ÉTICA EM PESQUISA}

Não se aplica.

\section{CONFLITO DE INTERESSES}

Não se aplica.

\section{LICENÇA DE USO}

Este artigo está licenciado sob a Licença Creative Commons CC-BY-NC. Com essa licença você pode compartilhar, adaptar, criar para qualquer fim, sem uso comercial e desde que atribua a autoria da obra.

\section{HISTÓRICO}

Recebido em: 25-06-2019

Aprovado em: 09-02-2020 